\title{
Incidencia de los factores en la comprensión lectora de los estudiantes de décimo grado en la Institución Educativa Distrital Madres Católicas
}

\author{
The impact of the factors in the reading comprehension in tenth graders at \\ Institución Educativa Distrital Madres Católicas
}

\author{
John Jairo Herrera Navas \\ Especialista en la Enseñanza del Inglés de la Universidad del Norte, Tutor del Programa Todos Aprender MEN, Barranquilla, \\ Atlántico,johnherrnav@gmail.com \\ Rita María López Jiménez \\ Especialista en Pedagogía para el Desarrollo del Aprendizaje Autónomo de la Universidad Nacional Abierta y a Distancia \\ UNAD, Docente de Lenguaje en la I.E.D. Madres Católicas, Barranquilla, Atlántico, ritam473@hotmail.com \\ Yuleidys María Rodríguez Rambao \\ Licenciada en Idiomas Extranjeros de la Universidad del Atlántico, Docente bilingüe en el colegio David (David School), Ba- \\ rranquilla,Atlántico,yuleidys_rodriguez@hotmail.com

\section{Elsa Emilia Petit Torres} \\ Ph.D. En Ciencias Humanas. Docente Investigadora de la Universidad de Zulia, Venezuela elsapetitluzve@ gamial.com
}

Para citar este artículo: Herrera J., López R. , Rodriguez, Y., Petit E., (2017). Incidencia de los factores en la comprensión lectora de los estudiantes de décimo grado en la Institución Educativa Distrital Madres Católicas. Escenarios, 15(1), pp. 85-108. Doi: http:/ / dx.doi.org/10.15665/ esc.v15i1.1123

Recibido: enero 17 de 2017

Aceptado: febrero 20 de 2017

\section{RESUMEN}

La educación colombiana del siglo XXI exige el desarrollo de competencias lectoras en los estudiantes del país. En el presente estudio se identifican los factores que afectan el proceso lector en los estudiantes de décimo grado de la Institución Educativa Distrital Madres Católicas de Barranquilla. La investigación de naturaleza descriptiva y propositiva logra a partir de sus resultados analizar la prueba saber noveno grado e identificar los factores académicos que inciden sobre dicho proceso. Se aplicó autobiografía semiestructurada, una encuesta a estudiantes y otra a padres de familia; una entrevista a la docente de Lenguaje para conocer los factores personales y socioculturales inhibidores de variable objeto de estudio. Los datos arrojados comprueban que entre los factores académicos se revela dificultad en la interpretación de textos, la criticidad y la necesidad de apoyo para reflexionar. En los factores personales se reconocen la desmotivación y la falta de hábitos lectores como los de mayor incidencia y en los factores socioculturales predominó el contexto extratextual. Se concluyó que el factor académico fue el más afectado, solo el componente muestreo se constituye en dinamizador. En el nivel personal y sociocultural se encontró desinterés por la lectura y un especial gusto por el uso de las tecnologías. De acuerdo a estas características, se propone a la institución educativa adaptar el método de lectura autorregulada, IPLER, para ser implementado a través de una plataforma educativa virtual, como propuesta didáctica basada en la teoría de la confluencia 
de factores para mejorar el proceso de la compresión lectora en los estudiantes de décimo grado en la I.E.D. Madres Católicas de Barranquilla.

Palabras claves: confluencia de factores, comprensión lectora, I.E.D. Madres Católicas de Barranquilla

\begin{abstract}
The 21st century Colombian education demands the development of reading skills in the students of the country. The present study identifies the factors that affect the reader process in the tenth grade students at Institución Educativa Distrital Madres Católicas from Barranquilla. The research of descriptive and propositive nature achieves from its results to analyze the Prueba Saber Noveno and identifies the academic factors that affect the said process; Surveys were applied to students and parents and an interview to Spanish teacher to know about personal and sociocultural inhibitory factors of the variable object of study. The data shows that among academic factors there are difficulties in the interpretation of texts, criticality and the need for support to reflect; in the second, the lack of motivation and lack of reading habits were the ones with the highest incidence and in the third, the extratextual context prevailed. Based on the results, it was concluded that the academic factor was the most affected because only one of its components (sampling) was dynamic, complementary at the personal and sociocultural were found disinterest for reading and a pleasure for the use of technologies. According to these characteristics, it is proposed to the educational institution to adapt the IPLER method to be implemented through a virtual educational platform, as a didactic proposal based on the theory of confluence of factors to improve the reading process and motivate tenth graders at I.E.D. Madres Católicas from Barranquilla.
\end{abstract}

Key words: confluence of factors, reading comprehension, I.E.D. Madres Católicas de Barranquilla.

\section{INTRODUCCIÓN}

El Ministerio de Educación Nacional en Colombia a través de los lineamientos curriculares del área de lenguaje plantea ideas básicas para apoyar a los docentes en lo concerniente a desarrollar en los estudiantes competencias lectoras, con el fin de estimular personas capaces de construir su propio futuro y mejorar sus condiciones de vida (Lineamientos, 1998).

Nuestro equipo de investigación en respaldo científico al lineamiento curricular vigente para el desarrollo de competencias lectoras en los educandos, se interesó en estudiar los factores que inciden en la comprensión de este fenómeno específicamente en los estudiantes del décimo grado de la I. E. D. Madres Católicas de Barranquilla, a fin de ofrecer resultados útiles orientados a proponer lineamientos estratégicos para el desarrollo de políticas educativas que mejoren este proceso para desarrollar competencias en la población objeto de análisis. En este sentido, la definición del problema ha sido estructurada de la siguiente manera:

\section{Limitaciones y fortalezas asociadas a los facto- res académicos de la comprensión lectora.}

La comprensión lectora es uno de los problemas que más preocupa a los profesores de cualquier grado escolar, debido a que el Estado a través del Instituto Colombiano para la Evaluación de la Educación (ICFES), implementa las Pruebas Saber para $3^{\circ}, 5^{\circ}, 9^{\circ}$ y $11^{\circ}$ con el objetivo de evaluar las competencias, habilidades, valores y niveles de los estudiantes en diferentes áreas, como el lenguaje. No obstante, algunos de éstos 
resultados no se corresponden con las expectativas nacionales, razón por la cual ha interesado emprender el estudio de los factores asociados a ésta dificultad.

Una muestra clave para presentar la problemática anteriormente mencionada, se observa en la gráfica 1, el resultado de los niveles de desempeño en el área lenguaje de $3^{\circ}, 5^{\circ}$ y $9^{\circ}$ de las Pruebas Saber de los años 2012-2015.Este registro histórico muestra que de un año a otro crece negativamente el nivel insuficiente y mínimo en el desempeño del área objeto de estudio.

Gráfica 1: Niveles de desempeño en lenguaje y matemáticas para $3^{\circ}, 5^{\circ}$ y $9^{\circ}$. Nacional

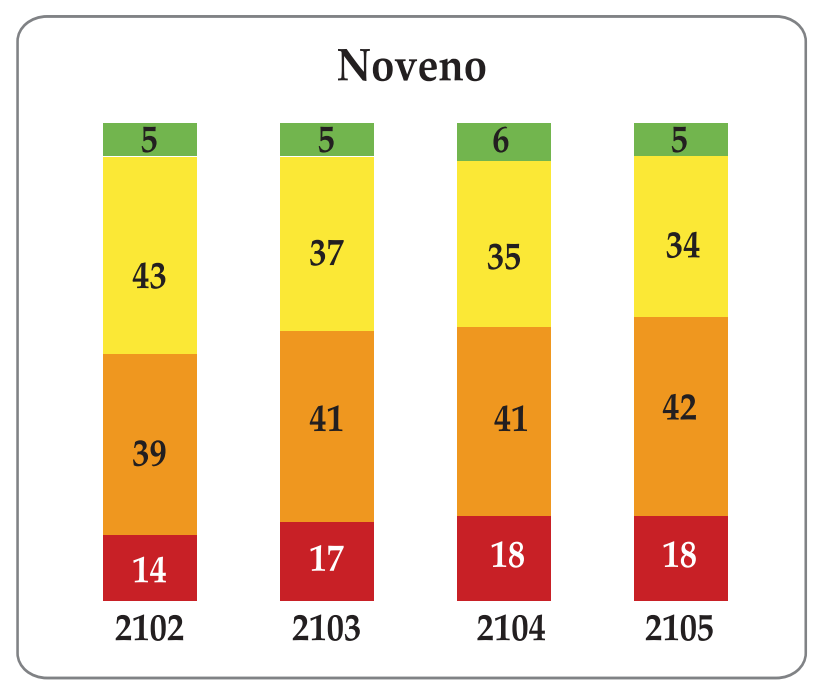

Gráfica 1. Resultado de los niveles de desempeño de lenguaje de $3^{\circ}, 5^{\circ}, 9^{\circ}$ de las Pruebas Saber de los últimos años (2012, 2013, 2014 y 2015). Tomado de la $4^{\text {a }}$ edición del boletín Saber en Breve, marzo de 2016.

El nivel insuficiente del desempeño en el área Lenguaje, de 2012 fue del 14\%, 2013 del 17\%, 2014 del 18\%, 2015 se mantuvo en el 18\%; en el nivel mínimo en el 2012 fue del 39\%, 2013 del $41 \%$, 2014 se mantuvo en el $41 \%$ y en el 2015 del $42 \%$; confirmándose que se ha producido un decrecimiento o sostenimiento en el desempeño y los problemas asociados a las competencias de lectoescritura estudiantil, resultado por el cual se hace hincapié en la intención científica de reconocer los factores influyentes en la comprensión lectora como fenómeno de investigación.
Específicamente en Colombia, la Prueba Saber 9no. permite comparar resultados a nivel local y nacional en el marco de la evaluación del desempeño estudiantil que determina la competencia lectoescritura, tal como se evidencia a través de la gráfica 2.

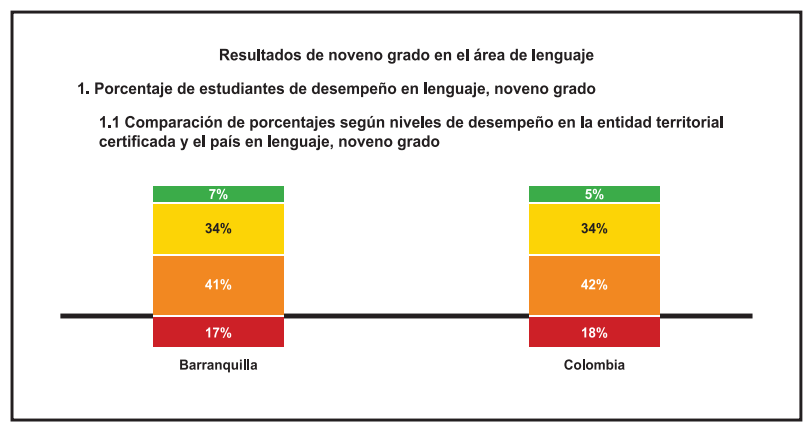

Gráfica 2. Resultados de Pruebas Saber de 9no. en el área de lenguaje a nivel distrital y nacional. Tomado de: Instituto Colombiano para la Evaluación de la Educación ICFES (2015).

Sobre los resultados obtenidos en la ciudad de Barranquilla el 17\% de los estudiantes se ubican en un nivel de desempeño insuficiente, el $41 \%$ en mínimo y en Colombia el $18 \%$ y $42 \%$ se encuentra en estos mismos rangos. Estos resultados reafirman la existencia del problema asociado a la comprensión lectora tanto a nivel distrital como nacional.

En el Informe por Colegio de la Prueba Saber 2015, realizado por el Instituto Colombiano para la Evaluación de la Educación (ICFES) sobre el desempeño de la IED Madres Católicas de Barranquilla, se encontró que los estudiantes del 9no., actuales estudiantes de décimo grado en la institución, traen a rastras dificultades en sus competencias de lectoescritura, específicamente en la comprensión de textos se encontraron datos bastante relevantes:

El 55\% de los estudiantes no contestó correctamente los ítems correspondientes a la competencia lectora en la prueba de Lenguaje. El 63\% de los ellos no relaciona, identifica y deduce información para construir el sentido global del texto. El $62 \%$ de los estudiantes no relaciona textos y moviliza saberes previos para ampliar 
referentes y contenidos ideológicos. El $55 \%$ de los estudiantes no reconoce elementos implícitos de la situación comunicativa del texto. El 55\% de los estudiantes no evalúa estrategias explícitas o implícitas de organización, tejido y componentes de los textos. El 55\% de los estudiantes no recupera información explícita en el contenido del texto. El 53\% de los estudiantes no identifica información de la estructura explícita del texto. El 50\% de los estudiantes no recupera información implícita de la organización, tejido y componentes de los textos (ICFES Prueba Saber 2015).

Los datos relacionados con los factores académicos revelan que hay dificultad para asumir posiciones críticas, demuestra necesidad de apoyo para comprensión de textos y el nivel de interpretación es bajo. Luego del anterior análisis se procedió a determinar los factores personales que influyen en la comprensión lectora de los estudiantes. En el proceso se pudo evidenciar que dentro de lo personal se encontró elementos como la motivación y los hábitos de lectura que hay factores relevantes en la dinámica de la comprensión lectora.

Influencia de factores personales en la dinámica de los procesos de comprensión lectora.

La comprensión lectora está asociada a la motivación por parte del lector. Desde esta perspectiva, si lo planteamos desde un plano volitivo es necesaria la actitud del lector a la hora de leer un texto. Si no encuentra un sentido emotivo por leer, tampoco tendrá gusto por este acto, es decir, debe haber una disposición desde el punto de vista emocional al momento de interpretar un texto.

En este sentido Solé (2010: 22) hace la relación entre motivación y éxito: "Los lectores más motivados leen más y más seriamente, con lo que se incrementa su competencia y su habilidad. Recíprocamente, el aprendizaje y la percepción de competencia aumentan la motivación, así que, con frecuencia, los estudiantes que apren- den son los más motivados y los que se implican más en la lectura".

Con el fin de dar respuesta al segundo objetivo específico que apunta a los factores personales, se aplicó una encuesta estructurada a los estudiantes; las preguntas con sus respectivas respuestas arrojaron que la desmotivación y falta de hábitos lectores inciden en el bajo desempeño de la comprensión.

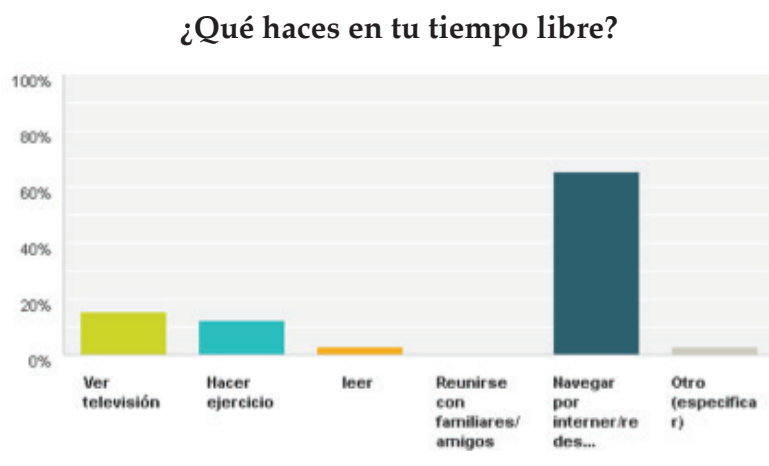

Gráfica 3. Resultado de la pregunta ¿qué haces en tu tiempo libre? de la encuesta aplicada a la estudiantes.

En la primera pregunta que apuntaba al tiempo libre de los estudiantes: ¿Qué haces en tu tiempo libre? El 65\% mencionó que navegar por internet y redes sociales, el 15,63\% dijo que ver televisión, el 12,50 \% dijo hacer ejercicio y solo un 3,13\% mencionó leer. Esto nos muestra que la lectura no hace parte de su tiempo libre lo cual lo observamos en la gráfica 3.

En este factor personal juega un papel principal la actitud que tiene el estudiante hacia la lectura y como esta se fortalece con la motivación. Por lo tanto, este hallazgo de desmotivación de la población objeto de estudio permite aclarar una de las causas del bajo desempeño de los estudiantes al interpretar un texto escrito.

Es tan marcada la percepción que se hace de la desmotivación para con la lectura que otra pregunta se enfocó en si realmente les gustaba leer y solo un porcentaje mínimo el 15,63\% respondió afirmativamente, como se puede observar en la gráfica 4. 


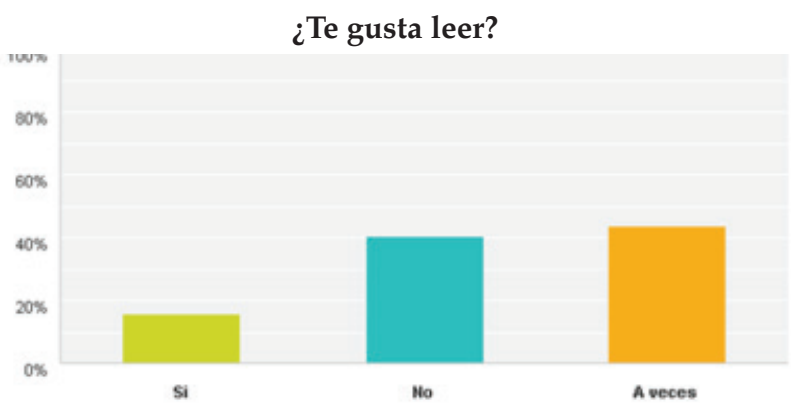

Gráfica 4. Resultado de la pregunta ¿te gusta leer? de la encuesta aplicada a la estudiantes.

De igual manera, otras preguntas buscaron hallar hábitos de lectura en los estudiantes y detectar con cuanta frecuencia leían libros. Los hallazgos permitieron encontrar que la mayoría de los estudiantes leen poco "¿Cuántos libros lees aproximadamente en un año?" de 0 a 2 libros el $56,25 \%$, de 2 a 4 libros el 31,25\%, de 4 a 6 libros el 12,50\% y ninguno dijo 6 en adelante. Esto nos muestra que la mayoría no lee libros impresos lo cual incrementa las dificultades lectoras de estos estudiantes pues al no leer cierta cantidad de libros se desmejora el proceso lector y se acentúa los problemas para comprender un texto.

Después de analizar los datos relacionados a los factores personales, se pudo evidenciar que la mayoría de estudiantes no leen en sus tiempos libres y no sienten interés por leer libros impresos, esto es relevante para la investigación, puesto que demuestra que hay una desmotivación para con la lectura y falta de hábitos que afectan el proceso lector de la población objeto de estudio.

Por último, los investigadores procedieron a determinar los factores socioculturales que influyen en la comprensión lectora de los estudiantes a través de la autobiografía y entrevista a la docente, los cuales fueron los instrumentos utilizados para analizar dicho factor.

El contexto sociocultural como factor asociado a la comprensión lectora.

Comprensión lectora es entonces una habilidad fundamental para las personas, útil a lo largo de toda la vida y en cada situación cotidiana, y no es necesario encasillarla dentro del contexto educativo. La lectura se desarrolla dentro y fuera del ámbito escolar y está condicionada por diversas variables de carácter sociocultural, subjetivo, educativo y textual (Ribes, 1990; Martínez Rizo, 2004).

Investigaciones precedentes han corroborado este planteamiento al mostrar que el desempeño lector se relaciona estrechamente con factores socioculturales (Mella \& Ortiz, 1999; de Jung, 2001; Andrews y Zmijewski, 1997; Bazán, 2004). En la autobiografía, la cual fue el instrumento utilizado para determinar los factores socio-culturales que inciden en la comprensión lectora de los estudiantes, se encontró que la familia y el estrato socio-económico influyen negativamente en el proceso lector de estos.

Como se puede evidenciar en las gráficas 5, el $88 \%$ de los estudiantes afirman que se influencian de manera negativa por sus padres; con esta información se puede concluir que los educandos no tiene un buen ejemplo en casa que los influencie positivamente con respecto a la importancia que tiene la lectura lo largo de la vida.

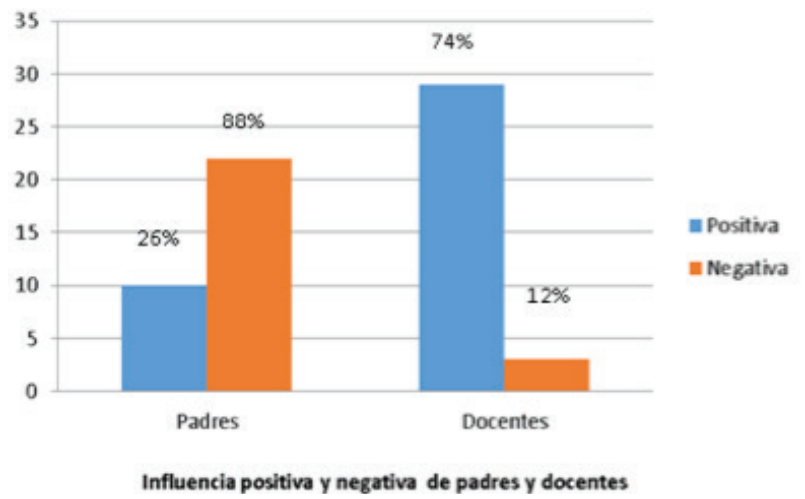

Gráfica 5. Resultados de la influencia positiva y negativa de padres y docentes.

De igual manera, en la gráfica 6, el 53\% de los estudiantes afirmaron que sus padres no les dan razones para leer, es decir, que en casa no se fomenta el hábito de lectura, lo que desconoce la importancia de esta en la formación del individuo para la sociedad. 


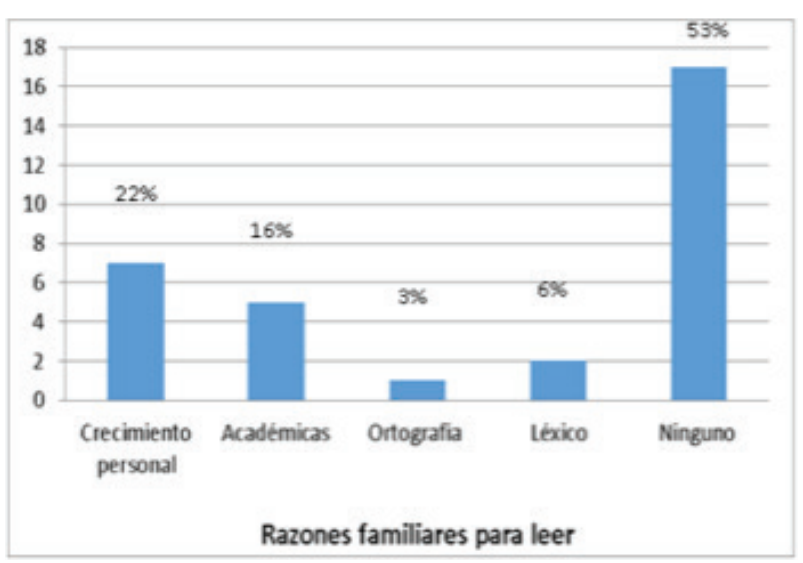

Gráfica 5. Resultados de las razones familiares para leer.

$\mathrm{Al}$ analizar algunos factores socioculturales relacionados con la comprensión lectora como lo son el contexto intratextual y extratextual, se concluye que los padres influyen de manera negativa el proceso lector de los estudiantes porque mientras los papás no apoyen y den ejemplo a sus hijos del gusto por la lectura, ellos tampoco sentirán motivación por esta.

Conscientes de los factores que están asociados con el proceso lector de los estudiantes de décimo grado de la I.E.D. Madres Católicas de Barranquilla se busca formular lineamiento para el diseño de una propuesta didáctica basada en la teoría de la confluencia de factores para mejorar el proceso de la comprensión lectora de la población objeto de estudio.

Cada uno de los anteriores factores: Académicos, personales y socioculturales poseen indicadores que orientan la trayectoria científica y nuestra intención de investigación hacia el análisis de aquellos factores dinamizadores o inhibidores de la comprensión lectora, en este caso, sintéticamente para describir la situación de los estudiantes de décimo grado en la I.E.D. Madres Católicas.

En este sentido expuesto, los factores que se mencionaron anteriormente llevan a revisar si se facilita o no la comprensión lectora del sujeto, en este caso el estudiante, pero no se evidencia de manera aislada, la relación entre algunos de ellos son determinantes al momento de evaluar si se encuentra en un nivel favorable o no de la lectura (Castellanos, 2007).
La relación entre los factores es estrecha; con los personales se analiza la actitud, la motivación, los hábitos y el uso del tiempo libre, entre otros; con los académicos, las habilidades obtenidas en la escolaridad; y con los socioculturales, el entorno familiar y el escolar de ese lector, es decir, el contexto en que se desenvuelve.

Algunas de las afirmaciones de Castellanos (2007) giran en torno a que la influencia tanto del entorno familiar del estudiante como del social moldea sus hábitos de lectura, así como la motivación. Esta, proveniente de los padres extrínsecamente determina el rendimiento escolar, por tanto, el apoyo para la realización de las actividades escolares es fundamental. El autor plantea la indiscutible relación existente entre los indicios del factor académico y el nivel de comprensión lectora que alcanza. Por último, expone que la capacidad adquisitiva, determinada por el nivel socioeconómico al cual pertenece, es un indicador significativo en el factor sociocultural (pág. 77 y 78).

Como consecuencia de toda la revisión teórica expuesta, es necesario definir una investigación que estratégicamente posibilite trabajar desde esos factores actividades didácticas, por supuesto, con respecto a los indicios relevantes que predominen en la población objeto de estudio.

Cuando se establezca la correlación manifiesta, de dirigirán actividades de facilitación con asertividad pedagógica para mejorar la comprensión lectora, de la misma manera el desempeño académico de las disciplinas objeto de estudio, la aprehensión, la competencia en los diferentes ámbitos, toda vez que la lectura se convierte en vehículo mediador del proceso de aprendizaje.

Los argumentos expuestos anteriormente permiten plantear la siguiente pregunta de investigación: ¿Cuáles factores inciden en la comprensión lectora de los estudiantes de décimo grado de la I. E. D. Madres Católicas de Barranquilla?

Al comenzar desde la anterior pregunta y el problema planteado por esta investigación se 
buscó la respuesta a partir del siguiente Objetivo general: Analizar los factores asociados a la compresión lectora de los estudiantes de décimo grado en la I.E.D. Madres Católicas de Barranquilla.

\section{METODOLOGÍA}

Este estudio con enfoque cuantitativo, está basado en el método de estudio de caso único, lo cual hace que esta investigación sea irrepetible, y de carácter revelador, pues permite mostrar a la comunidad científica un estudio que no hubiera sido posible conocer de otra forma (Yin, 1993).

La estrategia cuantitativa fue seleccionada como la más apropiada debido a que la cuantificación de los datos constituye un procedimiento con estadística descriptiva, y en el proceso de conocimiento, la objetividad se entiende, para este caso, como la no intervención de cualquier elemento afectivo en la relación que se establece entre el observador y el observado (Monje, 2011).

A su vez, la metodología cuantitativa se relaciona con el abordaje porcentual de los resultados del tema a estudiar en los factores que inciden en la comprensión lectora de los estudiantes de décimo grado en la I.E.D Madres Católicas de Barranquilla. Esta investigación permitió emprender el análisis de factores académicos, personales y socioculturales como variables estadísticas.

Se utilizaron la encuesta, la autobiografía y la entrevista como técnicas e instrumentos de recolección de datos que permitieron recoger la información en la institución objeto de estudio (Orozco, 1997: 31).

El uso del estudio de caso como método de investigación cuantitativa se justifica para este trabajo porque está centrado en comprender dinámicas presentes en contextos singulares, es un estudio particular y complejo de un único caso; y permite utilizar distintos métodos para la recogida de evidencia con el fin de contrastar los resultados obtenidos con la teórica utilizada (Martínez Carazo, 2011).
El estudio de caso es considerado por Stake (2007) como "el estudio de la particularidad y de la complejidad de un caso singular, por el que se llega a comprender su actividad en circunstancias concretas" (p.40).

\section{Selección del caso y sus criterios de selección}

\begin{abstract}
- Selección de I. E. D. madres católicas como referente empírico. El referente de investigación es la Institución Educativa Distrital Madres Católicas, de carácter oficial, ubicada en el Suroccidente de la ciudad de Barranquilla. Desde hace cinco años El referente de investigación es la Institución Educativa Distrital Madres Católicas, de carácter oficial, ubicada en el Suroccidente de la ciudad de Barranquilla. Desde hace cinco años aproximadamente, está enfocada con su cuerpo de profesores y la comunidad educativa en generar procesos encaminados a la mejora continua a través de la implementación de un modelo pedagógico, la reestructuración de procesos curriculares a través de la malla curricular, los planes de área y proyectos institucionales.
\end{abstract}

La I. E. D. Madres Católicas en su condición de institución distrital, hasta la fecha se caracteriza por recibir apoyo restringido por parte del ente territorial, debido a que la infraestructura no pertenece al Estado, se encuentra en concesión (ahora en trámite esta circunstancia). Durante el período anteriormente citado ha contado con tres rectores, el último asumió el cargo en mayo de 2016, lleva el liderazgo a mayores cambios con miras a mejorar resultados, en particular en las pruebas externas donde éstos hasta ahora se han presentado bajos en algunos periodos y altos en otros.

Al realizar el análisis de resultados de las pruebas SABER 2015, en particular en 9no grado, se evidenció que estos manifiestan una acentuada deficiencia en la lectoescritura, lo que llevó a este grupo de investigación a estudiar los reportados por la prueba en el componente lector como eje del proceso formativo, toda vez que a través de las directrices del Ministerio de Edu- 
cación Nacional, MEN, se estimula a la mejora continua, en particular al desarrollo de habilidades y destrezas para formar estudiantes competentes.

\section{Instrumentos}

Luego de identificar las variables, se procedió a determinar los instrumentos que se utilizaron para recolectar y registrar la información pertinente para identificar qué factores inciden en la comprensión lectora de los estudiantes de décimo grado de la I.E.D. Madres Católicas de Barranquilla. Entre los instrumentos se encuentran.

PUEBA SABER 9no: Es un cuadernillo de pruebas elaborado por el ICFES y el Ministerio de Educación de la República de Colombia, que se le aplica periódicamente a los estudiantes de noveno grado de los establecimientos educativos, oficiales y privados, urbanos y rurales, para monitorear el desarrollo de las competencias básicas para contribuir al mejoramiento de la calidad de la educación en el país.

La prueba evalúa las competencias en lenguaje, matemáticas y ciencias naturales o cultura ciudadana. Todas las preguntas son de selección múltiple con única respuesta, en las cuales se presentan el enunciado y cuadro opciones de respuesta, denominadas A, B, C, D. La prueba tiene 54 preguntas para cada competencia; En lenguaje se evalúan cinco factores: (a) producción textual; (b) comprensión e interpretación textual; (c) literatura, que supone un abordaje de la perspectiva estética del lenguaje; (d) medios de comunicación y otros sistemas simbólicos; y (e) ética de la comunicación, un aspecto transversal a los cuatro factores anteriores.

Después de haberse aplicado la prueba, El ICFES entrega reportes de resultados a los establecimientos educativos participantes y también por municipios y/o departamentos, con sus respectivos puntajes promedio y niveles de desempeño en cada área y grado. En la siguiente gráfica, se presentan los distintos tipos de reportes:

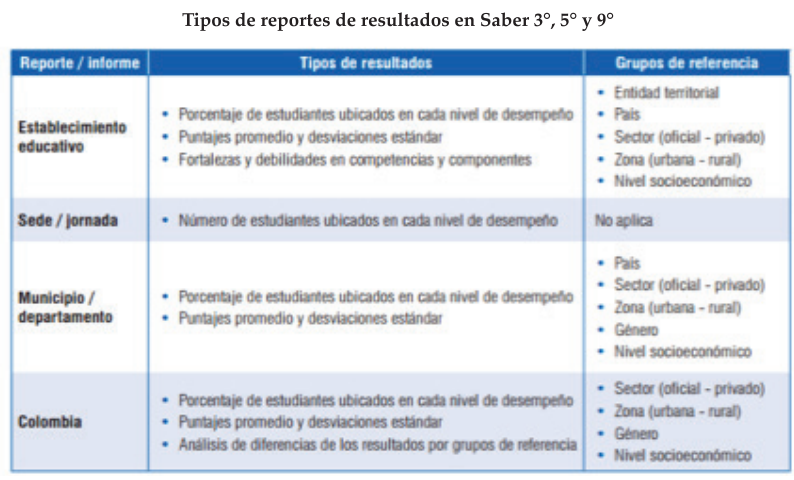

Gráfica 8. Tipos de reportes de resultados en Saber $3^{\circ}, 5^{\circ}$ y $9^{\circ}$. Tomado de PRUEBAS SABER $3^{\circ}, 5^{\circ}$ y $9^{\circ}$. Lineamientos para las aplicaciones muestral y censal (2014).

ENCUESTA \# 1: la primera encuesta tiene un diseño explicativo-pragmático, puesto que esta investigación pretende determinar la contribución de factores a la causación de un fenómeno (Monje 2011). Esta fue elaborada con el propósito de analizar los factores personales que inciden sobre el proceso de comprensión lectora de los estudiantes de décimo grado de la I.E.D. Madres Católicas.

La encuesta mide el hábito de lectura y la motivación como factores personales, con 10 preguntas estructuradas y sus posibles opciones de respuesta. Éste instrumento fue validado por cinco expertos en el área de lenguaje para comprobar si era efectivo para medir los factores personales en estudiantes de décimo grado.

ENCUESTA \# 2: la segunda encuesta también tiene un diseño explicativo-pragmático. Esta fue elaborada con el propósito de analizar los factores personales que inciden sobre el proceso de comprensión lectora de los estudiantes de décimo grado de la I.E.D. Madres Católicas. Se aplicó a 31 padres de familia de la población objeto de estudio.

La encuesta mide el conocimiento que tienen los progenitores acerca del hábito de lectura y la motivación de sus hijos, con 10 preguntas estructuradas y sus posibles opciones de respuesta. Éste instrumento fue validado por cinco expertos en el área de lenguaje para comprobar si era efectivo para medir los factores personales en estudiantes de décimo grado. 
ENTREVISTA: se diseñó una entrevista con el propósito de analizar los factores académicos, personales y socio-culturales que inciden sobre el proceso de comprensión lectora de los estudiantes de décimo grado de la I.E.D. Madres Católicas. Se entrevistó a una sola docente, por ser la encargada del área de lenguaje en el grado objeto de estudio.

La entrevista contó con 12 preguntas estructuradas donde la docente tuvo la oportunidad de responder de manera cerrada o abierta bajo las circunstancias requeridas. Éste instrumento fue validado por cinco expertos en el área de lenguaje para comprobar si era efectivo para medir los factores personales, académicos y socio-culturales a través de la opinión de su docente.

LA AUTOBIOGRAFÍA: Este método fue utilizado a partir de las afirmaciones de Geertz (1995) y Holstein \& Gubrium (1997), quienes afirman que la autobiografía ha sido considerada como un método científico serio, que puede ser útil dentro de un proceso de investigación. Por otro lado, un estudio realizado por Zussman (2000) concluye que la autobiografía puede ser la mejor metodología disponible para el estudio de procesos psicosociales y socio-culturales.

La autobiografía fue utilizada para identificar factores socio-culturales en la población objeto de estudio. En ella los 31 estudiantes de la población de interés, que se constituyó en un censo, por ser todos ellos los que debían narrar cómo ha sido su experiencia con relación a la lectura desde niños hasta el presente, guiándose por 7 preguntas de referencia. Las preguntas utilizadas para direccionar la aplicación de la autobiografía, fueron validadas por 5 expertos en el área de lenguaje, para comprobar si era efectivo para medir los factores socio-culturales en estudiantes de décimo grado.

Los resultados de cinco instrumentos aplicados, permitirán a los investigadores analizar los factores que inciden sobre el proceso de compresión lectora en los estudiantes de noveno grado de la I.E.D. Madres Católicas.

\section{ANALISIS DE DATOS}

Factores académicos que inhiben la comprensión lectora en los estudiantes del décimo grado desde la perspectiva de los resultados pruebas saber 2015 y el informe por colegio de la I.E.D. madres católicas de barranquilla.

Para analizar los factores académicos que se inhiben la comprensión lectora en los estudiantes del décimo grado del a I.E.D. Madres Católicas se tuvo en cuenta los resultados de los siguientes informes: Informe entidad territorial certificada: Barranquilla, Informe descriptivo del ICFES, Informe por colegio del ICFES, Índice Sintético de Calidad, Informe por colegio Prueba Saber 9: Aterrizando los resultados al aula. Teniendo en cuenta los datos de los instrumentos utilizados para el desarrollo de esta investigación se encontraron los siguientes factores 
Tabla 1. Factores Académicos que inhiben o dinamizan la comprensión lectora en los estudiantes del décimo grado según el Informe por Colegio de LA I.E.D. Madres Católicas.

\begin{tabular}{|c|c|}
\hline \multicolumn{2}{|c|}{$\begin{array}{l}\text { FACTORES ACADEMICOS QUE INHIBEN Y DINAMIZAN LA COMPRENSION } \\
\text { LECTORA SEGÚN EL INFORME POR COLEGIO } 2015\end{array}$} \\
\hline INHIBIDORES & DINAMIZADORES \\
\hline $\begin{array}{l}\text { Factor Lector: } \\
\text { - La predicción: Los estudiantes evidencian dificultad al anticipar contenidos y for- } \\
\text { mular hipótesis. } \\
\text { - La inferencia: Los estudiantes evidencian dificultad para deducir y concluir informa- } \\
\text { ción explícita, lo que afecta la autocorrección. } \\
\text { - Los conocimientos previos: existe una clara deficiencia en los estudiantes al mo- } \\
\text { vilizar los conocimientos previos para la comprensión del texto. } \\
\text { - Nivel de desarrollo cognitivo: Los estudiantes evidencian dificultad para asimilar, } \\
\text { acomodar o comprender la nueva información. } \\
\text { - Situación Emocional: La realidad afectiva de los estudiantes afecta su comprensión } \\
\text { en el momento de la lectura, siendo un aspecto personal, redunda en lo académico. }\end{array}$ & $\begin{array}{l}\text { Factor Lector: } \\
\text { Muestreo: se evidencia } \\
\text { capacidad en los estudian- } \\
\text { tes para seleccionar pala- } \\
\text { bras e ideas significativas } \\
\text { del texto. }\end{array}$ \\
\hline INHIBIDORES & DINAMIZADORES \\
\hline $\begin{array}{l}\text { - Competencias del lenguaje: se evidencia en los estudiantes, debilidad en el domi- } \\
\text { nio de la lengua, léxico, sintaxis y modo de usarla. }\end{array}$ & \\
\hline Factor Texto: (no aplica) & Factor Texto: (no aplica) \\
\hline $\begin{array}{l}\text { Factor Contexto: } \\
\text { - Textual: se evidencia dificultad en los estudiantes para establecer las relaciones } \\
\text { entre un enunciado y las ideas que le rodean en el mismo. } \\
\text { - Extra textual: siendo los aspectos externos al texto y el lector estos se hacen evi- } \\
\text { dentes al analizar los factores socio-culturales. } \\
\text { - Psicológico: siendo que este se refiere al estado de ánimo del lector al leer, éste } \\
\text { se evidencia a través del análisis de los factores personales. }\end{array}$ & Factor Contexto: \\
\hline
\end{tabular}

Elaborado por: Herrera, López \& Rodríguez (2017). Resultados e interpretación de la entrevista a docente de lengua castellana. Barranquilla, Colombia.

A través de la síntesis anterior se coteja que existen tres factores académicos determinantes para el Ministerio de Educación Nacional que inciden en la comprensión lectora, cada uno de ellos con subniveles que según el caso determina capacidades (Factor Lector), factores (Factor Texto), condiciones (Factor Contexto); requieren evidenciar el desarrollo de habilidades puntuales, al ser comparadas éstas con los resultados de la Prueba Saber $9^{\circ}$ en el Informe por colegio, refleja el origen del alto porcentaje de resultados desfavorables en la comprensión de textos.

En la consolidación de la información se establece que el factor texto no aplica, por cuanto éste se encuentra bajo la acción de quien lo produce (escribe) mas no bajo el control del lector y esta competencia no es objeto de la presente investigación.

En el factor lector, se encontró que la mayor parte de las capacidades a desarrollar son inhibidores del proceso, es decir, que los estudiantes tienen dificultades al anticipar contenido, formular hipótesis, deducir y concluir explícitamente, movilizar los conocimientos previos, comprender nueva información y deficiencia en el dominio léxico. Por tanto se debe intervenir en cada uno de ellos para potencializar las habilidades de los estudiantes a la hora de analizar un texto determinado.

El muestreo, a diferencia de las demás capacidades se situó como factor dinamizador, con lo que se demuestra que los estudiantes tienen la 
capacidad para seleccionar palabras e ideas significativas del texto.

Por otro, la condición emocional como factor académico, se podrá analizar con mayor claridad desde los factores personales, por tanto se da un primer punto de encuentro. De la misma manera en el factor contexto se da una situación similar al establecer la relación con la condición del contexto psicológico al ser constatable a través de los factores personales, es entonces el segundo punto de encuentro en la confluencia entre factores.

Factores personales que influyen en el desempeño de la comprensión lectora de los estu- diantes del décimo grado en la I.E.D. Madres Católicas de Barranquilla.

Para analizar los factores personales que influyen en el desempeño de la comprensión lectora en los estudiantes del décimo grado de la I.E.D. Madres Católicas, se aplicaron encuestas a los estudiantes y padres de familia para identificar elementos relevantes del factor personal que inciden en la comprensión lectora de los estudiantes como son la motivación y actitud para con la lectura, así como interés personal de los mismos. Teniendo en cuenta los datos de los instrumentos utilizados para el desarrollo de esta investigación se encontraron los siguientes factores.

Tabla 2. Factores personales que influyen en el desempeño de la comprensión lectora de los estudiantes de décimo grado de la I.E.D. Madres Católicas.

FACTORES PERSONALES QUE INFLUYEN EN EL DESEMPEÑO DE LA COMPRENSION LECTORA DE ESTUDIANTES DEL DECIMO GRADO EN LA I.E.D. Madres Católicas.

\begin{tabular}{|c|c|c|}
\hline $\begin{array}{l}\text { FACTOR PERSONAL } \\
\text { (ESTUDIANTE) }\end{array}$ & DESCRIPCION & $\begin{array}{l}\text { FACTOR PERSONAL } \\
\text { (PADRES DE FAMILIA) }\end{array}$ \\
\hline \multirow{4}{*}{ Desmotivación } & $\begin{array}{l}\text { Los estudiantes están interesados más en las redes sociales } \\
\text { que en la lectura. }\end{array}$ & \multirow{4}{*}{ Desmotivación } \\
\hline & Los estudiantes no sienten gusto por la lectura. & \\
\hline & Los estudiantes leen solo para informarse y por motivos escolares & \\
\hline & $\begin{array}{l}\text { Los estudiantes no les gusta leer contenidos políticos, científicos, } \\
\text { enciclopédicos o biográficos }\end{array}$ & \\
\hline \multirow{2}{*}{ Hábito lector } & Los estudiantes leen solamente dos libros al año. & \multirow{2}{*}{ Hábito lector } \\
\hline & Los estudiantes no leen frecuentemente fuera del horario escolar. & \\
\hline
\end{tabular}

Al tener en cuenta la tabla 2, se puede observar que hay una correspondencia entre las percepciones de los estudiantes y de los padres de familia, en ambas percepciones se afirma que la desmotivación y la falta de hábito lector influyen negativamente sobre el proceso lector de los estudiantes. Como se justifica a continuación a partir de la teoría.

La data refleja que los estudiantes están desmotivados intrínsecamente con relación a la lectura, puesto que a ellos no les gusta leer y que cuando lo hacen solo es por motivos escolares o para informarse a través de redes sociales. Éste es un factor personal relevante, puesto que la motivación intrínseca es considerada la más importante, debido a que esta refleja la propensión natural del ser humano para aprender y asimilar (Ryan y Deci, 2000).

Se identificó la falta de hábitos de lectura que va ligada con la desmotivación de los estudiantes por hacer una rutina que les permita adquirir conocimiento y / o placer hacia la lectura, como 
afirma Landa (2005) “cuando se experimenta la lectura como algo que tiene que ver con nuestro yo más íntimo, se logra un placer o al menos, un bienestar o confort interior que uno quiere volver a sentir" (p.7). Por consiguiente, los estudiante de décimo grado aún no han conocido su yo interno que les manifieste placer por leer, pero esto solo lo lograran cuando hayan alcanzado un buen hábito lector.

El hábito lector es un factor personal relevante, debido a que los maestros deben promover el goce por la lectura en las escuelas, en nuestras manos está que cultivemos en nuestros estudiantes la necesidad de leer en su vida diaria (Fowler, 2000). La afirmación mencionada anteriormente constata que los docentes tienen el compromiso de promover estrategias que generen hábitos de lectura hacia un mejor desempeño.
Después de analizar los factores personales, los investigadores procedieron a analizar los Factores Socio-culturales que inciden en la comprensión lectora de los estudiantes del décimo grado en la I.E.D. Madres Católicas de Barranquilla.

Factores Socio-culturales que inciden en la comprensión lectora de los estudiantes del décimo grado en la I.E.D. Madres Católicas de Barranquilla desde la interpretación simbólica de los actores involucrados.

Basado en la autobiografía y parte de la encuesta aplicada a los padres, los cuales fueron los instrumentos utilizados para identificar los factores socio-culturales que inciden en la comprensión lectora de los estudiantes, se encontraron los siguientes datos:

Tabla 3

Factores Socioculturales que inciden en la comprensión lectora de los estudiantes del décimo grado en la I.E.D. Madres Católicas de Barranquilla desde la interpretación simbólica de los actores involucrados.

\begin{tabular}{|l|l|}
\hline \multicolumn{1}{|l|}{ INTERPRETACION SIMBOLICA DEL ESTUDIANTE } & INTERPRETACION SIMBOLICA DE LA FAMILIA \\
\hline $\begin{array}{l}\text { Contexto extra textual: influencia de padres y do- } \\
\text { centes para con la lectura. } \\
\begin{array}{l}\text { Los estudiantes se ven influenciados de manera neg- } \\
\text { ativa hacia la lectura en por sus padres. }\end{array}\end{array}$ & $\begin{array}{l}\text { Contexto extra textual: Lugar y materiales para leer en } \\
\text { casa. } \\
\text { hogares para realizar actividades de lectura. }\end{array}$ \\
$\begin{array}{l}\text { leer. } \\
\text { Los padres de los estudiantes no les dan razón para } \\
\text { lectura. }\end{array}$ & $\begin{array}{l}\text { Los estudiantes tienen material para leer en sus hog- } \\
\text { ares. }\end{array}$ \\
\hline $\begin{array}{l}\text { Los padres consideran que existen algunas condi- } \\
\text { ciones didácticas y ambientales apropiadas para la } \\
\text { lectura. }\end{array}$
\end{tabular}

Con respecto a los factores socioculturales que influyen el proceso de comprensión lectora de los estudiantes de décimo grado, notamos que el primer factor contexto extra textual es la influencia del entorno familiar en la lectura de los estudiantes. Como parte del proceso extrínseco de motivación dentro del factor socio cultural, los padres consideran que motivan a la lectura. Sin embargo, al corroborar esto con lo que piensan sus hijos se observa que no es cierto, dado que los padres no motivan a sus hijos a leer desde la perspectiva de los jóvenes.
Se afirma que los padres no son un ejemplo para con sus hijos en el tema de la lectura y esto se convierte en aspecto negativo del proceso lector para los estudiantes. Desde la perspectiva teórica se visibiliza la necesidad de la supervisión de la lectura por parte de los progenitores con apoyo en la elaboración de las actividades asignadas, de esta manera se puede influir positivamente en la comprensión lectora (Morles, 1975). Esto implicaría una intervención a los padres a partir de una estrategia que dé respuesta al desarrollo de las capacidades lectoras tanto en la escuela como en casa. 
Lo que si hay es una influencia positiva de los docentes en la lectura de los estudiantes, es decir, solo la escuela es el lugar en donde los estudiantes realmente desarrollo el hábito lector. Es digno de resaltar que la lectura se debe desarrollar dentro y fuera del ámbito escolar y está condicionada por diversas variables de carácter sociocultural, subjetivo, educativo y textual (Ribes, 1990; Martínez Rizo, 2004).

Los sustentos teóricos nos permiten proponer una estrategia que posibilite la práctica de la lectura en casa, para que se la transferencia positiva sobre las actividades de aula (González, 2004); donde el docente adquiera el rol de guiar el proceso, el padres se convierta en un apoyo en casa y el estudiante en líder de su propio cambio.

Por otro lado, el segundo factor está relacionado con lugar y materiales para leer en casa. Es así como Thorndike (1973) señala que los recursos de lectura existentes en el hogar y el estatus socioeconómico de la familia son los dos factores que se relacionan más estrechamente con la comprensión lectora.

Así mismo, hay autores que mencionan diversos factores socioculturales entre los que están la cantidad de libros, los distintos textos utilizados para realizar tareas escolares, la supervisión de la lectura por parte de los padres y el apoyo en la elaboración de tareas, tienen una influencia beneficiosa en el desarrollo de la comprensión lectora (Morles, 1975).
Confluencia de factores para mejorar el proceso de la compresión lectora en los estudiantes de décimo grado en el instituto I.E.D. Madres Católicas de Barranquilla.

Luego de analizar e interpretar los resultados arrojados por los estudiantes y padres de familia, el equipo investigador decidió tomar en consideración la percepción de la docente que estuvo a cargo de la asignatura de lengua castellana, por esto se aplicó una entrevista con el objetivo de poder establecer la confluencia de los factores, debido a que ella fue la que tuvo contacto con la población objeto de estudio.

Este proceso se basó en las bases teóricas de Castellanos (2007:26) quien afirma que el lector se relaciona con ciertas características personales, con su nivel educativo, económico y sociocultural. Esto nos permitió diseñar una entrevista semiestructurada que tenía como finalidad analizar la relación existente de los factores personales, académicos y socioculturales con el nivel de comprensión lectora.

Así mismo, la información recolectada brindó la oportunidad de hacer la contrastación con los elementos desarrollados en el marco teórico. A continuación se hace una interpretación de la entrevista a través una tabla en la que se explica los datos arrojados y su relación con cada uno de los factores asociados a la problemática investigada. La información se puede observar en la tabla 4. 
Tabla 4 Resultados e interpretación de la entrevista a docente de lengua castellana

\begin{tabular}{|c|c|}
\hline INFORMACIÓN GENERAL & OBSERVACIONES DEL ENTREVISTADOR \\
\hline $\begin{array}{l}\text { Fecha de la entrevista: } 2 \text { de Enero de } 2017 \\
\text { Lugar de la entrevista: I.E.D. Madres Católicas de } \\
\text { Barranquilla. } \\
\text { Nombre del entrevistado: Nora Molina } \\
\text { Profesión del entrevistado: Lic. En Lenguas Modernas. }\end{array}$ & $\begin{array}{l}\text { La entrevista se desarrolló en la sala de profesores } \\
\text { de la Institución Educativa Distrital Madres Católicas } \\
\text { de Barranquilla con el fin de brindar un ambiente } \\
\text { agradable y calmado para que la profesora se sintiera } \\
\text { cómoda. } \\
\text { Se realizó las siguientes anotaciones en las cuales } \\
\text { se logrón apreciar la influencia de cada factor en la } \\
\text { comprensión de lectura de los estudiantes. }\end{array}$ \\
\hline ESQUEM & INTERPRETACIÓN SIMBÓLICA DE LA DOCENTE \\
\hline $\begin{array}{l}\text { Factores académicos: } \\
1^{\circ} \text {. ¿Considera que los estudiantes de décimo interpretan } \\
\text { con facilidad los textos que leen? } \\
2^{\circ} \text {. ¿Usted cree que los estudiantes de décimo interpretan } \\
\text { y critican las lecturas que tienen cierto grado de } \\
\text { complejidad? } \\
3^{\circ} \text {. ¿En su opinión, cuando los estudiantes de décimo se } \\
\text { leen texto se detienen a reflexionar sobre la posición del } \\
\text { autor? } \\
\text { Factores socioculturales: } \\
4^{\circ} \text {. ¿De las siguientes opciones, cuál es el tipo de lectura } \\
\text { que tienen los estudiantes de décimo en sus hogares? } \\
\text { - Novelas; ciencia ficción; terror; toda clase de textos. } \\
5^{\circ} \text {. En términos generales, ¿cuál es el estatus socio- } \\
\text { económico al que pertenecen los estudiantes de décimo } \\
\text { grado? } \\
\text {-Alto; medio; bajo. } \\
6^{\circ} \text {. ¿Usted cree que en casa los padres de familia } \\
\text { supervisan lo que leen los estudiantes de décimo? } \\
7^{\circ} \text {. ¿En su opinión, los estudiantes de décimo tienen } \\
\text { apoyo en el hogar cuando realizan sus tareas? } \\
\text { Factores personales: } \\
8^{\circ} \text {. ¿Usted considera que los estudiantes de décimo } \\
\text { encuentran motivación en la escuela para leer? } \\
9^{\circ} \text {. ¿Usted piensa que los estudiantes muestran apatía } \\
\text { hacia la lectura? } \\
10^{\circ} \text {. ¿Los padres de familia les hablan a sus hijos sobre } \\
\text { la importancia de la lectura? } \\
11^{\circ} \text {. ¿Existe un ambiente en el hogar de los estudiantes, } \\
\text { adecuado para leer? } \\
12^{\circ} \text {. ¿Crees que existen lecturas interesantes para la } \\
\text { edad de los estudiantes? }\end{array}$ & $\begin{array}{l}\text { Factores académicos } \\
\text { - Los estudiantes de décimo se les dificulta interpretar } \\
\text { textos con facilidad por falta del hábito lector. } \\
\text { - En su mayoría los estudiantes no tienen ese grado } \\
\text { de criticidad en las lecturas que tienen grado de com- } \\
\text { plejidad. } \\
\text { - Los estudiantes de décimo necesitan la orientación } \\
\text { del maestro para lograr reflexionar sobre la posición } \\
\text { del autor. } \\
\text { Factores socioculturales } \\
\text { - La educadora estableció que estudiantes de decimo } \\
\text { tienen en sus hogares en el tipo de lectura novela ju- } \\
\text { venil. } \\
\text { - La maestra mencionó que los estudiantes de decimo } \\
\text { pertenecen a un estatus social bajo. } \\
\text { - La mentora aseveró que los padres de familia no } \\
\text { supervisan lo que leen los estudiantes de décimo. } \\
\text { - La docente puntualizó que los estudiantes de décimo } \\
\text { no tienen un apoyo mayor y mejor en el hogar cuando } \\
\text { realizan sus tareas. } \\
\text { Factores personales: } \\
\text { - Los estudiantes de décimo encuentran motivación } \\
\text { en la escuela para leer porque existe un programa } \\
\text { de lectura y se les motiva en las clases con lecturas } \\
\text { atractivas para ellos. } \\
\text { - La instructora manifestó que la mayoría de los estu- } \\
\text { diantes no les gusta leer. } \\
\text { - Según la docente los padres de familia no tienen esa } \\
\text { cultura de leer. } \\
\text { - En los estudiantes de decimo no existe un ambiente } \\
\text { adecuado para leer. } \\
\text { - Para la licenciada es necesario atraer a los estudian- } \\
\text { tes con lecturas interesantes. }\end{array}$ \\
\hline
\end{tabular}

Fuente: Elaboración de los autores

Como se muestra en tabla 4, hay una relación entre los tres factores incidentes en la comprensión lectora de los estudiantes de décimo grado. Desde la teoría de la confluencia de los factores se hace necesario el análisis de cada factor y como aporta elementos que influyen en el pro- ceso lector pues no pueden ser tomados de manera aislada, los tres factores se interconectan para aportar al desempeño de los aprendices.

Según Marín (1997, citado por Rosa María Castellanos, 2007) plantea que el acto de lectura es 
complejo puesto que convergen en él, aspectos como la intelectualidad, el estado de ánimo y la emocionalidad del individuo. Entonces se nota que debe darse la relación entre estos tres factores: el académico, el personal y el sociocultural al momento de leer un texto.

En primera instancia, en la entrevista se pudo notar que en el factor académico la docente aseguró que los estudiantes presentan dificultades a la hora de interpretar un texto, no tienen criticidad y necesitan apoyo para reflexionar en lo que leen, esto se pudo corroborar al analizar los resultados académicos de la prueba saber de noveno grado.

Dentro del fundamento teórico que soporta este trabajo de investigación en el factor académico hay habilidades fundamentales para la comprensión lectora necesarias al momento de leer e interpretar un texto según Morles (1999) son: Habilidad de inferencia, habilidad de síntesis, habilidad lectora y memoria. Estas capacidades deben ser desarrolladas en los estudiantes para que logren un buen desempeño en la comprensión textual.

En segunda instancia, la entrevista permitió apreciar el factor sociocultural pues la docente mencionó que los estudiantes tienen en sus hogares el tipo de lectura novela juvenil, pertenecen a un estatus social bajo y que los padres de familia no supervisan lo que leen. En este sentido lo que consideran Thorndike (1973) concerniente a los recursos de lectura existentes en el hogar y el estatus socioeconómico de la familia y lo que dice González (2004) acerca de las actividades que los padres realizan para promover la habilidad en cuestión incrementan la motivación intrínseca y favorecen el aprendizaje de los hijos, son factores que se relacionan estrechamente con la comprensión lectora.

En tercera instancia, en la entrevista se evidenció que el factor personal estuvo determinado por dos elementos: la motivación y el hábito lector. El primero de estos es referenciado por la docente cuando señaló que en la escuela a los estudiantes de décimo se les motiva para leer puesto que existe un programa de lectura con textos acorde a sus intereses y necesidades. Mientras que en el segundo elemento, la profesora afirmó que la mayoría de los estudiantes no les gusta leer, en sus hogares los padres de familia no tienen esa cultura de leer, y no se brinda un ambiente adecuado para leer.

En concordancia con la motivación, es necesario señalar que la actitud que tienen los estudiantes hacia la lectura influye notablemente en el fortalecimiento de esta habilidad, tanto del sujeto como de las personas en su entorno inmediato, en este caso de sus padres. La lectura es un acto comunicativo complejo que implica, además de lo intelectual, disposición emocional o estado de ánimo (Marín, 1997).

Por otra parte, en lo que corresponde al hábito lector el desarrollo de un hábito no debe verse como una acción obligada, sino más bien como una actividad placentera y de mucha motivación, que debe ser orientada con mucha organización y planificación. Es así como autores como Landa (2005) conectan el acto lector a una experiencia con nuestro yo interno que produce satisfacción.

Finalmente, el análisis y la interpretación de los datos recogidos, proporcionaran elementos contundentes de juicio lógico para apuntar a los objetivos de esta investigación, así como, brindó más soportes que dieran respuesta a la pregunta de investigación. Por consiguiente, los resultados obtenidos a través de los diferentes instrumentos aplicados, se ordenaron, clasificaron y presentaron en gráficas y tablas procesadas y sistematizadas.

\section{Propuesta didáctica basada en la teoría de la confluencia de factores para mejorar el proce- so de la compresión lectora en los estudiantes de décimo grado en la I.E.D. Madres Católicas de Barranquilla.}

Para cumplir con el anterior objetivo, los investigadores parten de los resultados de los instrumentos aplicados, los cuales arrojaron una realidad frente a la confluencia de factores asociados a la comprensión lectora; es por ello que 
los investigadores plantean lineamientos estra- los estudiantes de décimo grado los cuales se tégicos para mejorar la comprensión lectora de pueden observar en la siguiente tabla.

Tabla 9. Diseño de una propuesta didáctica basada en la teoría de la confluencia de factores para mejorar el proceso de la compresión lectora en los estudiantes de décimo grado en la I.E.D. Madres Católicas de Barranquilla.

\begin{tabular}{|c|c|c|c|}
\hline & FACTORES & ESTRATEGIA & ACTORES \\
\hline 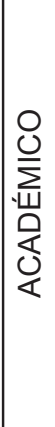 & $\begin{array}{l}\text { El lector } \\
\text { La predicción } \\
\text { La inferencia: } \\
\text { Los conocimientos previos } \\
\text { Nivel de desarrollo cognitivo } \\
\text { Situación Emocional } \\
\text { Competencias del lenguaje } \\
\text { El contexto } \\
\text { Textual: } \\
\text { Extra textual } \\
\text { Psicológico }\end{array}$ & $\begin{array}{l}\text { A partir de los factores académicos analizados bajo } \\
\text { esta investigación, los investigadores proponen el } \\
\text { método IPLER, adaptado a las necesidades de la } \\
\text { población objeto de estudio, sus intereses y los tex- } \\
\text { tos de tipo literario. } \\
\text { El método comprende tres momentos, un antes, un } \\
\text { durante y un después de la lectura, cada uno de } \\
\text { ellos cuenta con acciones concretas a realizar por } \\
\text { el lector para permitir la significatividad y la autor- } \\
\text { regulación. }\end{array}$ & $\begin{array}{l}\text { El estudiante: como re- } \\
\text { sponsable directo de su } \\
\text { proceso de crecimiento y } \\
\text { formación. } \\
\text { El docente: quien va a } \\
\text { impartir las instrucciones } \\
\text { para el manejo del método. } \\
\text { Padres: quienes deben ver- } \\
\text { ificar el cumplimiento de los } \\
\text { resultados del IPLER. }\end{array}$ \\
\hline & $\begin{array}{l}\text { La desmotivación } \\
\text { La falta de hábitos de lec- } \\
\text { tura }\end{array}$ & $\begin{array}{l}\text { La motivación: se convierte en un factor determi- } \\
\text { nante para favorecer la comprensión de lectura, } \\
\text { tanto extrínseca como intrínsecamente. En el prim- } \\
\text { er caso, la valoración del trabajo realizado debería } \\
\text { ser suficiente para el estudiante, pero como no ha } \\
\text { sido es caso, los investigadores proponen el méto- } \\
\text { do IPLER a través el medio virtual para favorecer } \\
\text { tanto las capacidades académicas como la moti- } \\
\text { vación. } \\
\text { En el segundo caso, este grupo investigativo con- } \\
\text { sidera que la motivación intrínseco depende del } \\
\text { individuo mismo si se tiene en cuenta la postura } \\
\text { de Turnage y Muchinsky, 1976, cuando afirman que } \\
\text { las actuaciones del individuo se dan sin buscar rec- } \\
\text { ompensa, por tanto en este caso de estudio es de- } \\
\text { terminante trabajar desde el interior de los estudi- } \\
\text { antes con apoyo motivacional a través de talleres } \\
\text { que favorezcan la generación de nuevas respues- } \\
\text { tas de los individuos por auto superación. } \\
\text { Formación de hábitos: ya que la motivación } \\
\text { logrará que los actos repetitivos, voluntarios se } \\
\text { conviertan en hábitos, como lo sostiene María José } \\
\text { del Valle, } 2012 \text {. Por esta razón los investigadores } \\
\text { proponen que se utilice el método IPLER virtual- } \\
\text { mente de manera constante. }\end{array}$ & $\begin{array}{l}\text { El estudiante: como re- } \\
\text { sponsable directo de su } \\
\text { proceso de crecimiento y } \\
\text { formación. } \\
\text { El docente: Como guía en } \\
\text { el proceso de generación de } \\
\text { hábitos lectores. } \\
\text { Orientador escolar: apoyo } \\
\text { para el docente con el } \\
\text { fin de trabajar un plan de } \\
\text { estímulos acorde con las } \\
\text { edades y necesidades del } \\
\text { contexto. } \\
\text { Padres: quienes motivaran } \\
\text { a sus hijos a través de la in- } \\
\text { dagación de los textos que } \\
\text { leen. }\end{array}$ \\
\hline & FACTORES & ESTRATEGIA & ACTORES \\
\hline 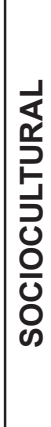 & El contexto extra textual. & $\begin{array}{l}\text { Escuela y docentes: generar talleres de formación } \\
\text { a través de la escuela de padres para que se } \\
\text { conozca el método IPLER para facilitar el apoyo en } \\
\text { casa para lograr el estímulo a la lectura y otras que } \\
\text { permitan hacer notar el papel determinante que } \\
\text { ejercen en sus hijos o acudidos a través del ejemp- } \\
\text { lo, deben quedar tareas clara a realizar a partir de } \\
\text { ese diálogo. Se debe hacer notar que no solo los } \\
\text { recursos y el ambiente apropiado son suficientes, } \\
\text { que su cercanía al proceso formativo (lector) que } \\
\text { muestra una mayor incidencia. }\end{array}$ & $\begin{array}{l}\text { Padres: comprometidos en } \\
\text { el apoyo del proceso lector } \\
\text { en casa y la generación de } \\
\text { nuevos hábitos lectores de } \\
\text { los hijos desde el ejemplo. }\end{array}$ \\
\hline
\end{tabular}




\section{CONFLUENCIA DE FACTORES}

Con base en la teoría se afirma que el factor académico se relaciona estrechamente con el personal y el sociocultural puesto que el apoyo recibido en las actividades escolares y la motivación de los padres para con sus hijos contribuye a la mejora de la comprensión lectora (Castellanos, 2007). Por consiguiente, se diseñó una estrategia didáctica que integra los factores en la medida en que cada uno de los actores del proceso asume con responsabilidad las acciones de su rol.

La estrategia didáctica presenta un esquema IPLER adaptado a las necesidades del plan lector y su respectiva rubrica de verificación con el fin de desarrollar las etapas de lectura y potencializar las habilidades (factor académico). Este se aplicará a través de una plataforma virtual llamada Edmodo, para favorecer la motivación y la generación de hábitos lectores (personal); por último se abrirá el espacio en la institución para realizar talleres a los padres de familia, para involucrarlos en el proceso (sociocultural).

La integración de todos los pasos descritos permitirá la mejora de la comprensión lectora a través de la confluencia de los mismos factores.

Fuente: elaboración de los autores, 2016

En la tabla anterior se puede observar los lineamientos planteados por los investigadores entre los cuales proponen que:

- Implementar el método IPLER adaptado virtualmente y de manera constante.

- Generar talleres de formación a través de la escuela de padres para que se conozca el método IPLER para facilitar el apoyo en casa.

- Realizar talleres que favorezcan la generación de nuevas respuestas de los individuos por auto superación.

Para implementar el método IPLER adaptado, los investigadores se basaron en los siguientes fundamentos teóricos:

\section{Método IPLER}

Para sustentar teóricamente la propuesta de la presente investigación, se parte del Documento de Apoyo Técnico (DAT, 1999), emitido por un convenio entre Caja de Compensación Familiar (CAFAM), y la Universidad Nacional Abierta y a Distancia (UNAD) bajo la dirección de Luís Delfín Insuasty, PhD; así como del documento presentado por Gloria Cecilia Ruales en 2013, para la UNAD en dependencias de San Juan de Pasto.

Ambos autores mencionan que el IPLER es un proceso de lectura autorregulada con la finalidad de favorecer el proceso de aprendizaje (conceptualización), “creado en 1940 por Ro- binson y en 1984 fue señalado por Johns y Mc Nema como un método para obtener un buen rendimiento académico" (Insuasty, 1999, pags. 64 a 66). El método comprende los tres momentos: antes, durante y después de la lectura que también se toman de Arrieta y Arrieta (2008), se relacionan a continuación las acciones a realizar de la siguiente manera: Antes de la lectura: Inspeccionar, Preguntar y predecir; Durante la lectura: Leer y valorar, Expresar; Después de la lectura: Revisar y consolidar.

\section{Acciones del trabajo en cada momento de lec- tura del método IPLER.}

A continuación se explican las acciones del trabajo en cada momento de lectura.

Antes de leer: se realizan dos pasos: Inspeccionar y predecir. En el primero (Inspeccionar): se da una mirada rápida al capítulo que se va a estudiar para obtener una información general, para lograrlo el método sugiere las siguientes actividades: Leer los títulos y subtítulos del capítulo; observar los encabezamientos de los dibujos, diagramas y tablas. Leer el resumen, si lo hay; leer la primera oración de cada párrafo; para tratar de encontrar palabras claves; observar las frases en negrita; leer las palabras del glosario.

En el segundo paso (Preguntar y predecir): se despierta el interés por el tema. Al lector se le solicita predecir o anticipar lo que le gustaría leer; transformar los títulos y subtítulos en preguntas; 
leer el cuestionario si lo trae; utilizar las preguntas de cuándo, cómo, para quién, con qué fin al cuestionarse por el contenido inspeccionado.

Durante la lectura: El primero corresponde a leer y valorar: Es lograr la máxima comprensión, para ello se requiere hacer una lectura silenciosa, analítica, comprensiva y dinámica; responder a las preguntas anteriores. La segunda acción apunta a expresar: se refiere a la habilidad del estudiante para construir nuevas relaciones, establecer nexos, resaltar conceptos acorde con la consulta o lectura propuesta.

Después de la lectura: la primera actividad es revisar y consolidar: Luego de haber leído y tomado notas, el lector organiza los resultados que reflejan lo aprendido por medio de: un resumen, un mapa conceptual o un ensayo, con lo cual demuestra su capacidad de transferencia de la temática a otros espacios cognoscitivos. Cada uno de los momentos y acciones anteriormente descritos se visibilizan a través de un formato sugerido al lector para dinamizar la organización y ejecución del método

Al tener en cuenta la anterior información los investigadores plantearon una adaptación del método IPLER para mejorar el desarrollo de la comprensión lectora de los estudiantes de Décimo grado de la I.E.D. Madres Católicas de Barranquilla.

Propuesta del método IPLER adaptado para la resolución de los factores asociados a la comprensión lectora de los estudiantes de décimo grado de la I.E.D. Madres Católicas de Barranquilla.

A través del análisis de datos, el estudio de la base teórica y el reconocimiento del contexto de la población objeto de estudio, este grupo de investigación seleccionó el método IPLER como base de la propuesta debido a las características que se han descrito anteriormente, en particular se destaca el manejo de los momentos de lectura y la búsqueda de transferencia en el proceso de ejecución del mismo, lo cual llevaría al estudiante (o usuario en general) a una lectura significativa.
Además de lo citado, con la presente propuesta se busca dar respuesta a la confluencia de los factores asociados a la comprensión lectora, por tanto las acciones a emprender buscan dar respuesta a las necesidades que se generan en cada uno de ellos y sus interrelaciones.

El método IPLER y su relación son los factores que inhiben en el proceso de comprensión lectora

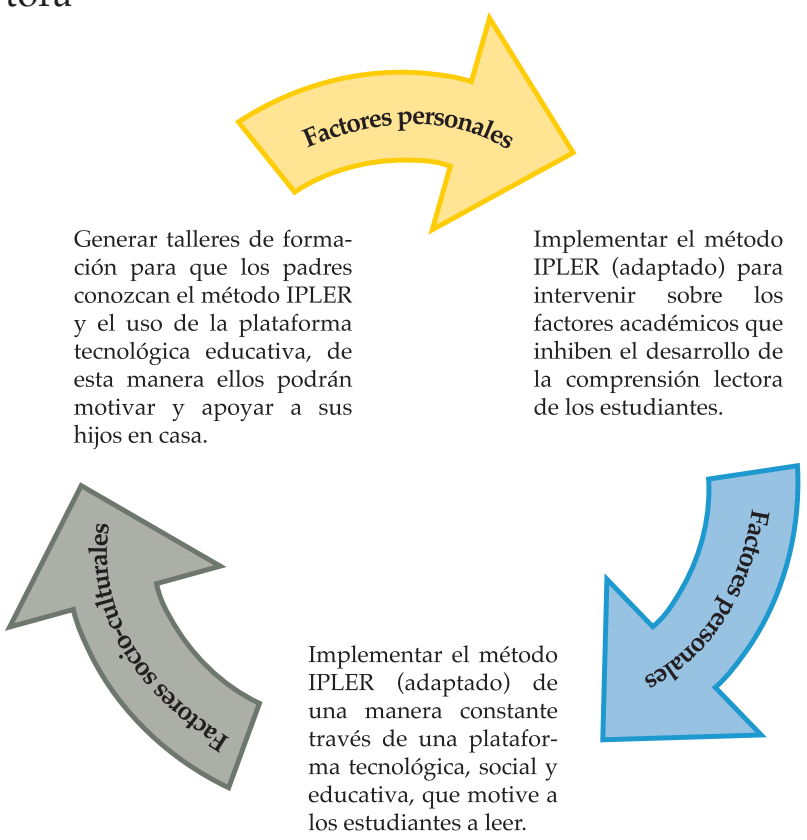

Gráfica 42. El método IPLER y su relación son los factores que inhiben en el proceso de comprensión lectora.

Las tres estrategias anteriormente esquematizadas explican la relación existente entre ellas y cómo se sustentan entre sí, para buscar que el proceso de comprensión lectora mejore en los estudiantes de décimo grado en la I. E. D. Madres Católicas, ya que cada situación problémica reflejada en el análisis de los factores se abarca en la propuesta. El eje del factor académico de la propuesta es el IPLER adaptado y con su implementación se busca estimular la motivación intrínseca, la generación de hábitos y el contexto extra textual.

Acciones del trabajo en cada momento de lectura del método IPLER (adaptado)

Para lograr el objetivo y como se puede observar en el instrumento que se encuentra a conti- 
nuación, las adaptaciones realizadas al IPLER son las siguientes:

Antes de la lectura: se cambia la lectura del glosario o lista de vocabulario por la elaboración de un listado del hallazgo de palabras desconocidas y la búsqueda del respectivo significado en contexto, de tal manera que se favorezca la apropiación de un nuevo léxico; se toma la lectura como un todo, por tanto no se hace la inspección de un solo capítulo de lectura sino se ejecuta esta acción capítulo por capítulo en texto completo para un único paso, para trabajar además el proceso con fragmentos o capítulos si así se requiere, y llevar con este paso a la concreción.

Otro aspecto que se modifica en esta primera parte es el manejo del hallazgo de gráficos, se estimula a la lectura de los mismos y luego a ubicar en el formato en qué página fue encontrado y describir la interpretación que de este hace el lector; en la formulación de preguntas se les invita a realizar las propias, estas serán construidas a partir de la inspección de los capítulos, de manera analítica y desde el plano personal o estudiantil, al procurar que con ello el estudiante mantenga la curiosidad, interés y se auto cuestione.

Por otro lado en la formulación de preguntas se le da libertad para la construcción desde cualquier aspecto que les haya llamado la atención en la inspección, únicamente se solicita tener un carácter analítico es decir, abordar un por qué, unas razones, causas u otros del mismo carácter.

Durante la lectura: los cambios consisten en exponerle al estudiante que busque las respuestas mentalmente, durante el proceso de la lectura misma, a las preguntas que se planteó en acción anterior, esto con el fin de no perder la concentración y el interés, para mantener la motivación intrínseca.

Después de la lectura: se plantea las siguientes modificaciones la acción de expresar a través de la elaboración de las idea fuerza cambia de momento, esto con el fin de lograr que la actividad sea más productiva, comprensiva y el estudiante logre con claridad plantear posibles respuestas a tres de las preguntas formuladas, desde la correlación entre el contenido de la obra y la realidad contextual (personal o estudiantil), esto permite evidenciar una reconstrucción de lo leído de manera significativa.

Al revisar y consolidar que es la última parte del método se piden dos acciones que también poseen cambios, en la primera se solicita la elaboración de una recomendación para otro posible lector, al emplear mínimo 5 palabras del vocabulario desconocido que halló, paso que favorece la consolidación de las ideas asimiladas mediante la lectura.

Como proceso máximo de transferencia, la última acción plantea una actividad creativa que permita llevar a otro medio la asimilación de la lectura misma; el docente tiene libertad para elegir otra que puntualmente le permita una transferencia con intensión específica.

\section{Rúbrica de verificación del IPLER}

Para facilitar la verificación de resultados del IPLER adaptado, se ha creado una matriz para que tanto al docente como el estudiante puedan determinar el alcance del trabajo ejecutado, que arroja además al final la valoración obtenida; favorece que se pueda alternar el método evaluativo, el docente concerta o decide si el ejercicio se hará auto, co o heteroevaluativamente.

\section{Uso del método IPLER a través de la platafor- ma edmodo}

Partiendo de la base de los resultados en la encuesta a los estudiantes, quienes reflejaron un alto interés y uso de las redes y los medios virtuales, este grupo plantea el uso del método a través de una plataforma educativa llamada Edmodo. Permite que haya una interconexión entre estudiantes y docente, el método se desarrolla virtualmente, se tiene control de momentos, tiempo de ejecución del proceso y de la publicación de resultados, contribuyendo a que el estudiante tenga curiosidad por el manejo de este proceso, el docente logre la medición de re- 
sultados que puede ir monitoreando por fases o en su totalidad y haciendo la retroalimentación a que haya lugar. El uso constante del método lleva a la adquisición de un hábito.

\section{¿Qué es Edmodo?}

en el microblogging creado para su uso específico en educación que proporciona a los docentes un espacio virtual privado en el que se pueden compartir mensajes, archivos y enlaces, un calendario de aula, así como proponer tareas y actividades y gestionarlas (Garrido, 2013).

Se trata de un servicio de redes sociales basado

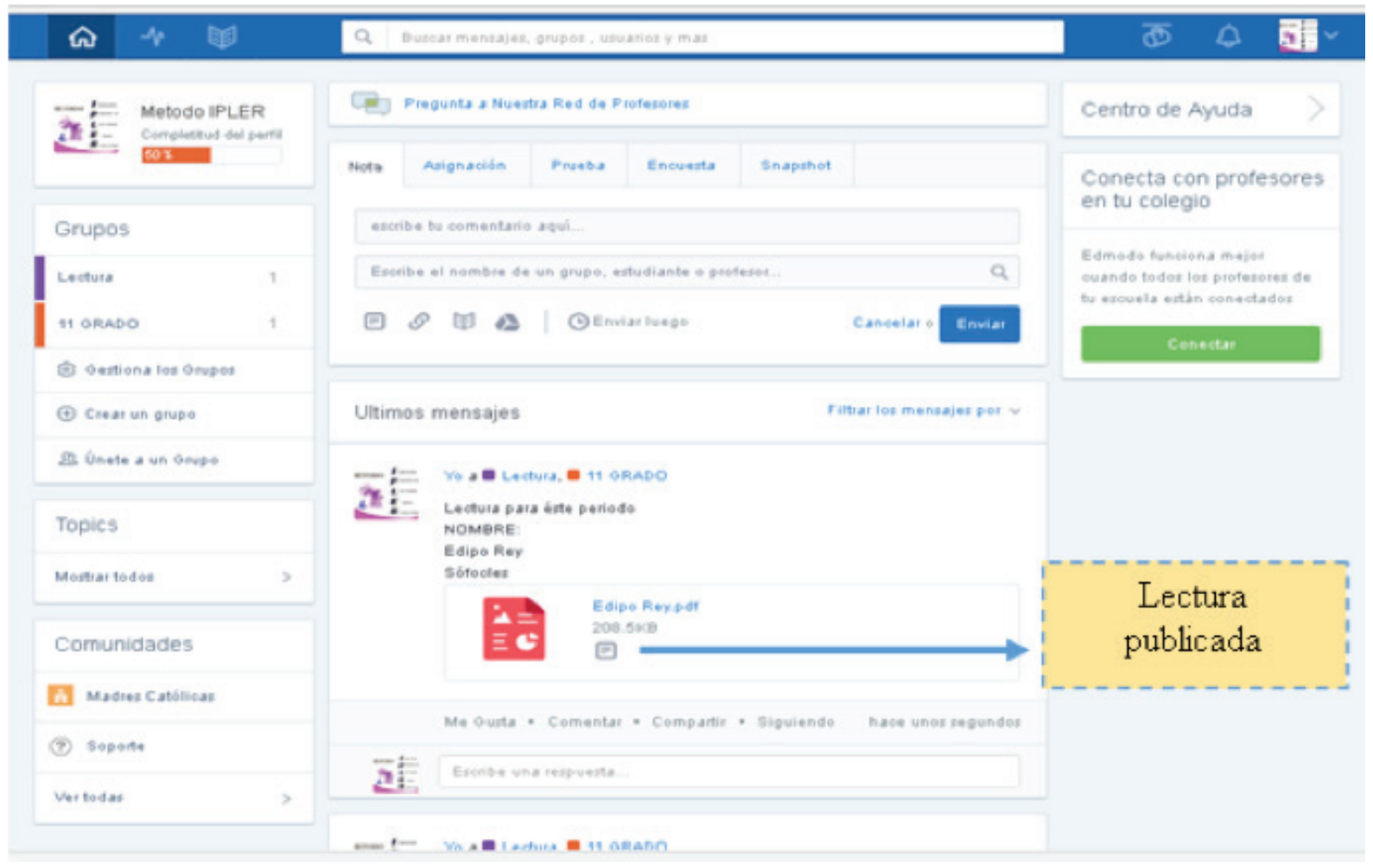

Fuente: www.edmodo.com

\section{Validación del método IPLER adaptado para} la resolución de los factores asociados a la comprensión lectora de los estudiantes de décimo grado de la I.E.D. Madres Católicas de Barranquilla.

Para la validación del método propuesto se tomó en consideración que en su condición original está ampliamente difundido y es conocido y/o empleado por algunos docentes en sus procesos de aula tanto en la básica secundaria como en pre -grado; este grupo de investigación presentó la adaptación a 21 docentes de Licenciatura en Lenguas Modernas de la ciudad de Barranquilla, quienes por ser expertos en el área de competencia podrán juzgar la pertinencia del mismo.
A estos profesores se les presentaron los siguientes documentos: un texto de consentimiento informado, una carta de solicitud de colaboración que trae consigo los objetivos a alcanzar, el método con la descripción del mismo y la rúbrica de verificación para recibir sus opiniones y firmas.

\section{Conclusiones}

Después de haber realizado todas las etapas correspondientes para dar la validez científica a este trabajo de investigación titulado: Factores que Inciden en La Comprensión Lectora de los estudiantes de décimo grado de la Institución Educativa Distrital Madres Católicas de Barran- 
quilla, se llegó a las siguientes conclusiones:

A partir del primer objetivo, se analizó un instrumento llamado prueba saber, el cual evidenció una data que permitió determinar los principales factores académico que inhiben y dinamizan el proceso de comprensión lectora de los estudiantes de décimo grado, entre los inhibidores se hicieron notorios: las falencias en la predicción, la inferencia, los conocimientos previos, el nivel de desarrollo cognitivo, la situación emocional, las competencias de lenguaje; el contexto textual, extra textual y psicológico. Como factor dinamizador únicamente se visibilizó la acción de muestreo que indica el nivel más elemental del lector.

Para el segundo objetivo, los investigadores aplicaron encuestas a estudiantes y padres de familia, las cuales permitieron analizar que los factores personales que afectan el proceso lector son la desmotivación y la falta de hábitos lectores. Un gran número de estudiantes expresaron no tener gusto por la lectura, no ser motivados por sus padres, $\mathrm{Y}$ desconocer la importancia que esta tiene para su desarrollo personal; sus preferencias se acercaban más al uso de las tecnologías.

La aplicación de una autobiografía dirigida a los estudiantes y parte de la encuesta a padres sirvió como insumo para responder el tercer objetivo. La data arrojada por los instrumentos evidenció que el factor socio-cultural que incide en el proceso de comprensión lectora de los estudiantes de décimo grado está relacionado con el contexto intra textual, puesto que los padres expresaron que tienen condiciones y recursos en casa para la lectura, los estudiantes prefieren otros tipos de actividades, mientras que los estudiantes expresan que sus padres no son ejemplo a seguir como lectores.

En la parte final del documento se formulan lineamientos estratégicos para el diseño de una propuesta didáctica basada en la teoría de la confluencia de factores, que da respuesta al cuarto objetivo, lo que fue posible al lograr analizar la entrevista a la docente quien toca con sus respuestas la relación entre los tres factores, cada uno en un momento de la misma, a través de la cual se verifica que existe concordancia con los datos de los estudiantes por ejemplo, al plantear que no existe una verdadera motivación a la lectura, otros recursos como la tecnología atraen su atención y falta mucho más apoyo y ejemplo de los padres para crear hábitos de lectura.

Con la propuesta antes mencionada se pretende mejorar el proceso de la compresión lectora en los estudiantes de décimo grado en la I.E.D. Madres Católicas de Barranquilla que lleve a generar no solo en los docentes sino para los estudiantes, estrategias didácticas con miras a mejorar la comprensión lectora de los segundos, para ello se propone utilizar el método IPLER adaptado, empleado a través de una plataforma virtual educativa, con el fin de dar respuesta y emplear a favor los intereses de los estudiantes.

Al generar esta estrategia para la consolidación de hábitos de lectura y motivación intrínseca, lo que este grupo de investigación logra relacionar son los factores personales y los académicos, debido a que el IPLER al ser un método adaptado para la lectura autorregulada, deposita en el estudiante la mayor responsabilidad en el desarrollo del mismo, por otro lado con la rúbrica visibilizan todos los actores del proceso, el alcance esperado en cada acción del método, a través de la rúbrica de verificación. Quiere decir entonces que tanto docente como estudiante aplican el proceso de evaluación del mismo que posibilita tanto la auto, como la co o heteroevaluación según sea programado.

Finalmente, se espera que la estrategia diseñada en este proyecto de investigación, la cual está fundamentada en las bases conceptuales de la confluencia de factores, sustentada por Castellanos (2007), sea un instrumento que permita mejorar la problemática de la comprensión lectora en la institución objeto de estudio.

\section{DISCUSIÓN}

Los resultados obtenidos en esta investigación fueron de gran importancia para el desarrollo 
de la misma, puesto que se pudo conocer una problemática real relacionada con la lectura en los estudiantes de noveno grado de la Institución educativa Distrital Madres católicas. Los datos nos arrojaron que hay tres factores que están perjudicando el desarrollo del proceso lector y que deben ser intervenidos porque la importancia de la lectura en el mundo en que vivimos es fundamental empezando porque es la herramienta más eficaz para restaurar y fortalecer el ámbito social y además juega un papel fundamental en el proceso de aprendizaje de los estudiantes.

A partir de las conclusiones anteriores el equipo investigador propone hacer algunas recomendaciones para la consecución y el buen desarrollo de la propuesta.

En primera instancia, la necesidad de un replanteamiento de los procesos lectores de la Institución en los que se integren los tres factores, la creación de espacios para el desarrollo de la lectura y su comprensión. Así mismo debe haber mayor integración entre lo leído y el contexto de los estudiantes que les permita despertar el interés hacía ésta, dinamizar la construcción de conocimientos y mejorar los niveles académicos.

En segunda instancia, para lograr la generación del hábito lector, el manejo del método y su rúbrica deben emplearse con regularidad para los procesos lectores, es decir que se emplee con la obra sugerida para el período en el plan lector de la institución, así como en los espacios de lectura de fragmentos y/o textos no literarios, lo que generaría un cambio para sus vidas y la interiorización del mismo.

En tercera instancia, la utilización de los recursos tecnológicos, para contribuir a fomentar el gusto por la lectura, además de la construcción de espacios gratificantes de aprendizaje para el desarrollo del área de lenguaje. Se espera que las estrategias pedagógicas aquí planteadas se tomen como punto de transformación educativa y de crecimiento personal, se pongan en marcha a la práctica de tal forma que los estudiantes exploten al máximo sus potencialida- des de comprensión y aprehensión de saberes. Todo ello enmarcado en la posibilidad de realizar mediciones de impacto de estos, el método posibilita los espacios de mediación, concertación y control de tiempos de ejecución con el fin de que docente y estudiantes pueden asumir nuevos retos.

En cuarta instancia, se recomienda a la institución generar espacios de divulgación del método y su rúbrica a los padres de familia, con ello se lograría su vinculación comprometida en el proceso lector, invitarlos a ser copartícipes del cambio en sus hijos y transformadores con el ejemplo y / o seguimiento.

\section{REFERENCIAS}

1. Andrews, J. \& Zmijewlki, G. (1997). How parents support home literacy with deaf children.

2. Arrieta, L. y Arrieta R. (2008). La didáctica de la lectoescritura a partir de experiencia docente. Colombia: Fundación Por Una Educación de Calidad.

3. Barrio, I. González, J. Padín, L. Peral, P. Sanchez, I \& Tarin, E. (2010). El Estudio de Casos. Métodos de investigación educativa, Universidad Autónoma de Madrid. $3^{\circ}$ Magisterio Educación Especial.

4. Bazán, A. Apoyo familiar, atribución de éxito y apego al PRONALEES como predictores del desempeño en lectura y escritura en el tercer grado. En Secretaría de Educación Pública (2002). Informes finales de investigación educativa. México: Secretaría de Educación Pública [SEP].

5. Castellanos, R. (2007). Factores relacionados con el nivel de comprensión lectora en estudiantes de secundaria. México. Universidad Nacional Autónoma de México, facultad de filosofía y letras, colegio de pedagogía. Tesis para licenciatura en pedagogía.

6. Fowler, V. (2000). La lectura, ese poliedro. Cuba: Biblioteca Nacional José Martí. 
7. Garrido, A. (2013). Edmodo. España: Creative Commons Attribution Non-commercial Share Alike 3.0 License. Recuperado de http: / / edmodo.antoniogarrido.es/index.html

8. Geertz, C. (1995). After the Fact: Two Countries, Four Decades, One Anthropologist. Cambridge, MA: Harvard University Press.

9. González, A. (2004). Estrategias de comprensión lectora. España: Síntesis.

10. Holstein, J.M. y Gubrium, J.F. (1997) Active Interviewing. In, D. Silverman (Ed.), Qualitative Research: theory, method and practice. London: Sage Publications.

11. Instituto Colombiano para la Evaluación de la Educación ICFES. (2015)Resultados de noveno grado en el área de lenguaje. Bogotá

12. Instituto Colombiano para la Evaluación de la Educación ICFES. (2016) Boletín Saber En Breve. Bogotá.

13. Instituto Colombiano para la Evaluación de la Educación ICFES. Resultados históricos en el área de lenguaje. Bogotá.

14. Insuasty, Luis (1999). Documento de Apoyo Técnico (DAT). Universidad Nacional Abierta y a Distancia. Bogotá.

15. Landa, M. (2005). Leer y escribir, vasos comunicantes. Revista de Educación, Número extraordinario.

16. Margín, A., (1997). Propuesta de modelo didáctico para la lectura recreativa en la secundaria. Recuperado el 18 de Agosto de 2016, de http: / / www.umass.edu / complit/alcanet / A_ Marin.html

17. Martínez C. (2011). El método de estudio de caso. Estrategia metodológica de la investigación científica". Universidad del Norte.

18. Martínez, F. ¿Aprobar o reprobar? (2004). El sentido de la evaluación en educación básica. Barranquilla. Colombia.
19. Mella, O., \& Ortiz, I. (1999). Rendimiento Escolar. Influencias diferenciales de factores externos e internos. Revista Latinoamericana de Estudios Educativos. 29.

20. Ministerio de Educación Nacional de Colombia, (1998). Lineamientos Curriculares Lengua Castellana. Santa Fe de Bogotá, D.C Cooperativa Editorial Magisterio.

21. Monje, C. (2011). Metodología de la Investigación Cuantitativa y Cualitativa. Guía Didáctica. Universidad Surcolombiana. Facultad de Ciencias Sociales y Humanas. Neiva: Colombia.

22. Morles, A. (1975). The scoring of cloze comprension test in the Spanichs language. Tesis de Maestría sin publicar. Universidad de Chicago. Mimeografiada.

23. Morles, A. (1999). El proceso de la comprensión en la lectura. En Revista Latina de Pensamiento y Lenguaje. 4-2B. Monográfico: Cognición, educación y evaluación. 279-293

24. Orozco Gómez, Guillermo. (1997). La investigación en comunicación desde la perspectiva cualitativa. México, Instituto Mexicano para el Desarrollo Comunitario (IMEC.

25. Ribes, E. (1990). Psicología general. México: Trillas.

26. Ruales, G. (2013). Método IPLER. Lectura Autorregulada. Universidad Nacional Abierta y a Distancia. San Juan de Pasto, Colombia.

27. Ryan, R., \& Deci, E. (2000). Self-determination theory and the facilitation of intrinsic motivation, social development, and well-being. American Psychologist, Vol. 55.

28. Solé, I. (2010). Ocho preguntas en torno a la lectura y ocho respuestas no tan evidentes. En Confirma 2010. Leer para aprender Leer en la era digital. (17- 24). España: Ministerio de Educación. Secretaría de Estado de Educación y Formación Profesional. 
29. Stake R.E (2007); Investigación con estudio de caso, Morata, Madrid, $4^{\text {a }}$

30. Tamayo, M. (2007). El proceso de la investigación científica. 4ta. Edición, México. Ed. Limusa.

31. Thorndike, R. (1973). La comprensión lectora: Educación en quince países. Nueva York: John Wiley.
32. Yin, Robert K. (1993). Applications of Case Study Research. London: SAGE, 1993.

33. Zussman, R. (2000). Autobiographical occasions: Introduction to the special issue. Qualitative Sociology, 23 (1), 58. 